\section{Kebab: can the traditional cooking process sanitize a natural contamination by Listeria monocytogenes?}

\author{
Paolo Bonilauri, ${ }^{1}$ Roberto Leonelli, ${ }^{1}$ \\ Gabriele Ferrarini, ${ }^{2}$ Diego Carobbi, ${ }^{2}$ \\ Maria Cristina Ossiprandi, ${ }^{3}$ \\ Michele Dottori, ${ }^{1}$ Antonio Cuccurese ${ }^{2}$ \\ ${ }^{1}$ Istituto Zooprofilattico Sperimentale \\ della Lombardia e dell'Emilia \\ Romagna, Reggio Emilia; ${ }^{2}$ AUSL di \\ Reggio Emilia, Servizio di Sanità \\ Pubblica Veterinaria, Reggio Emilia; \\ ${ }^{3}$ Dipartimento di Scienze Medico \\ Veterinarie, Università di Parma, Italy
}

\section{Abstract \\ Over the last few years a considerable} spread of ethnic foods was observed in Italy. Among them is the Döner kebab. During 2014-2015, in order to evaluate the effectiveness of traditional cooking process, raw product (defrosted), sliced cooked portions cut through electric knife and assembled sandwich were officially sampled in kebab houses and in a local industrial kebab producer in Reggio Emilia (a province in Italy). Microbiological researches for safety and hygienic microbiological indicators were carried out (research of Salmonella, Listeria monocytogenes, Campylobacter and Shiga toxin-producing Escherichia coli; enumeration mesophilic aerobic bacteria, lactic acid bacteria, sulfite-reducing bacteria growing under anaerobic conditions, yeasts and molds). Between the raw and the cooked product an average of $3 \log$ reduction in mesophilic aerobic bacteria counts was observed. In two out of three kebab houses sampled, which were supplied by the same local industrial producer, the presence of L. monocytogenes was detected. During the official inspection carried out at the production plant a contamination of $L$. monocytogenes was assessed in both ambient and instruments. Furthermore, 3 lots of products were analyzed and all were found to be contaminated by $L$. monocytogenes (always above $100 \mathrm{CFU} / \mathrm{g}$ ). In order to verify the capability of the traditional cooking process to reduce the risk of contamination at an acceptable level, a batch of naturally contaminated kebab (4.5 log CFU/g) was cooked and sliced simulating a day work activity in a kebab shop. The product was then sampled during preparation and enumeration of L. monocytogenes was obtained. After an hour of cooking, the residual contamination was $1.8 \log \mathrm{CFU} / \mathrm{g}$, after two hours and a half $L$. monocytogenes was no longer detectable in the product, but half an hour later it was again detectable in $25 \mathrm{~g}$. At the end of the experiment, the contamination grown up to the same level enumerated after an hour of cooking (1.8 log $\mathrm{CFU} / \mathrm{g})$. Considering the microbiological results, traditional cooking obtained a rate of $-2.40 \log \mathrm{CFU} / \mathrm{gh}^{-1}$, a $\mathrm{D}=26 \mathrm{~min}$ that corresponds to a temperature of maximum $60^{\circ} \mathrm{C}(\mathrm{z}=6)$. In conclusion, our experiment demonstrates the traditional kebab cooking process could not always guarantee a complete product decontamination.

\section{Introduction}

Muscle foods have a significant role in human diet because they are essential sources of vitamins and minerals. Nowadays people move across many different countries and the diverse ethnic groups have brought along their own food cultures increasing the diversity in the food available in the host country. Rapid changes in people's lifestyles increase the demand for convenience foods in the general food market and over the last few years a considerable spread of ethnic foods in the ready-toeat food market was observed in Italy as well. Among these is the döner kebab (sometimes known under different names, such as gyro, donair, dona kebab, souvlaki, chawarma or shawirma) that is a traditional Middle Eastern meat product made up of slices of meat interleaved with layers of raw meat resembling minced meat. For the production of kebab, firstly meat (1-6 mm thickness), minced meat and tallow (2-4 $\mathrm{mm}$ thickness) are marinated for 3 to 6 hours. Spice mixture is added and it may vary according to the manufacturer, but frequently it includes white pepper, black pepper, cumin, allspice, thyme. Grape juice or white sugar may be also used for the marination. At the end of the marination process meat, tallow and minced meat are impaled on a kebab stick respectively and shaped into a cone (Institute of Turk Standards, 1995). After production, the cone is often frozen and sold as it is to the retail shops. In the traditional kebab houses the cone of döner kebab is grilled on one side in a vertical position by means of a vertical rotating shovel that allows the meat cylinder to rotate near a heat source. When the first outer layer is sufficiently cooked, it is cut in thin slices by means of sharp knives (electric rotating knives are often used) and served as panini alone or together with a variety of sauces and vegetables.

Even though döner kebab is enjoyed in
Correspondence: Paolo Bonilauri, Istituto Zooprofilattico Sperimentale della Lombardia e dell'Emilia Romanda, Sede Territoriale di Reggio Emilia, via Pitagora 2, 42124 Reggio Emilia, Italy.

Tel.: +39.052.2921733

E-mail: paolo.bonilauri@izsler.it

Key words: Kebab; Listeria monocytogenes; traditional cooking process.

Contributions: the authors contributed equally.

Conflict of interest: the authors declare no potential conflict of interest

Funding: none.

Received for publication: 30 October 2017. Revision received: 16 January 2018.

Accepted for publication: 18 January 2018.

This work is licensed under a Creative Commons Attribution-NonCommercial 4.0 International License (CC BY-NC 4.0).

(C) Copyright P. Bonilauri et al., 2018

Licensee PAGEPress, Italy

Italian Journal of Food Safety 2018; 7:7167

doi:10.4081/ijfs.2018.7167

several places, there are some issues related to its microbiological quality and formulation. Microbiological risks associated with the product depend essentially on the microbiological quality of raw materials, hygienic working conditions, cooking methods, hygiene and sanitary conditions during the mechanical separation phases of the product and the time laps between preparation of sliced meat and the selling of panini to the final consumer.

Evidence of food hazards detected in kebab are reported in literature from the beginning of 80 s in Germany, where Jöckel $\mathrm{J}$ and Stengel G (1984) report a high prevalence of $\mathrm{Cl}$. perfingens $(10 \%)$ in ready to eat döner kebabs and Kruger KL and Davis ME (1999) detected 5.3-6.2 log $\mathrm{CFU} / \mathrm{g}$ staphylococci in $42 \%$ of döners sampled. In recent years, there have been a number of outbreaks of foodborne diseases associated with kebabs and products served in take-away restaurants. Between 1992 and 2007, thirteen outbreaks were reported in England and Wales ACMSF (2014), eleven of these were caused by Salmonella, one by vero-cytotoxigenic Escherichia coli $\mathrm{O} 157$ and one by Campylobacter. In a period of 18 years, between 2000 and 2017, the EU Rapid Alert System for Food and Feed RASFF (2017) received 97 notifications regarding kebab. Salmonella was the first cause of notifications (56, about 3 per year), 
followed at some distance by Listeria monocytogenes (5), other food hazards and adulterations.

Under the aegis of the Research Project Sibilla: use of predictive microbiology in official control of food business operator between 2014 and 2015, three gastronomies and one local industrial producer were enrolled on a voluntary basis in the project. Food safety and hygiene criteria were officially checked by Veterinary service. During this experience the efficacy of an experimental cooking process throughout a natural contamination of $L$. monocytogenes detected in raw kebab was assessed and the results are presented in this paper.

\section{Materials and Methods}

Three traditional kebab houses (A, B and $\mathrm{C}$ ) and a local industrial producer of kebab for internal market (Italy) were enrolled on voluntary basis, in the Research Project Sibilla: use of predictive microbiology in official control of food business operator, regional project (CUP:E45J10000110002).

A questionnaire was submitted to the three operators of the kebab shops regarding provenience, species of meat and size of kebab used; procedures for thawing meat before cooking, type of knife used, type of detergent/disinfectant used to clean the working tops, the time it takes to exhaust the kebab, sliced meat remnant time in the collecting pan and the destiny of kebab that remains at the end of a working day.

The local industrial producer was indeed asked the type of meat used (species), the origin of the raw materials, the manufacturing process, the size of kebab produced and the total amount of product produced per year.

\section{Sampling plan for microbiological analysis}

In the three gastronomies, three samples were collected, one of raw kebab (not yet cooked), one of sliced cooked kebab, and one of kebab that remained in the collecting pan and panini ready to be served with sauces and vegetables for a while. Environmental swabs $\left(100 \mathrm{~cm}^{2}\right)$ were taken from the working surface, the collecting pan and (manual and electric) knives during the working activity (swabs were not collected on washed and disinfected surfaces). A total of 36 kebab samples, (12 samples in each kebab house) were collected and a total of 15 environmental swabs ( 5 surfaces in each gastronomy) were sampled.

In the productive plant four official visits were conducted. During the first three, environmental samples on the working surfaces, the operating machines, such as churning machine and knifes, were collected together with 3 samples of raw kebab produced during the official audit, for a total of 9 samples of raw kebab and 30 environmental surfaces.

\section{Microbiological analysis}

All environmental swabs collected during the visits were analyzed for the presence of Salmonella spp. and Listeria monocytogenes by Real Time PCR with microbiological confirmation of positive signals (AFNOR 2008 and 2009, respectively).

For all kebab samples (raw kebab, sliced cooked kebab, kebab that remained in the collecting pan and panini ready to be served with sauces and vegetables) several microbiological parameters were investigated with an accredited laboratory according to ISO 17025:2005: enumeration of MAB (mesophilic aerobic bacteria) (ISO 48332:2013/Cor1:2014), enumeration of Enterobacteriaceae (ISO 21528-2:2004), enumeration of Beta-glucuronidase positive E.coli (ISO 16649-2:2001), enumeration of $\mathrm{LAB}$ (lactic acid bacteria) (MRS agar, $37^{\circ} \mathrm{C}$ and M17 agar, $37^{\circ} \mathrm{C} \pm 1^{\circ} \mathrm{C}$ in microaerophilic condition $5 \%$ of $\mathrm{CO}_{2}$ ) enumeration of sulfite-reducing bacteria growing under anaerobic conditions (ISO 15213:2003), enumeration of yeasts and molds (OGYEA agar, $21 \pm 1^{\circ} \mathrm{C}$ ), and research of Salmonella spp. (AFNOR 2008 + ISO 6579:2002/Cor 1:2004), research and enumeration of L. monocytogenes (AFNOR 2009 - 04/05 + ISO 11290-1:1996/Amd $1: 2004$ and ISO 11290-2:1998/Amd 1:2004), research of shiga toxin-producing Escherichia coli (ISO/TS 13136:2012) and research of Campylobacter spp. (REALTIME - IQ-CHECKTM CAMPYLOBACTER KIT (BIO-RAD) + ISO 102721:2006).

\section{Validation of traditional cooking process}

A cone of kebab of $12 \mathrm{~kg}$ naturally contaminated by Listeria monocytogenes (4.5 $\log \mathrm{CFU} / \mathrm{g}$ ) was cooked and sliced simulating a working day with a Döner kebab Machine (vertical kebab stick rotating in an open gas oven) during the Official Veterinary Audit in the productive plant. Meat was sampled before cooking (raw kebab) and during the kebab grilling and then slicing activity. Four sampling time of the cone were chosen: 1 . at the beginning of the kebab cone (after $1 \mathrm{~h}$ ), 2. in the middle of the kebab cone (after $2.5 \mathrm{~h}$ ), 3. at $3 / 4$ of cone consumption $(3 \mathrm{~h})$ and 4 . at the end of kebab cone (4h). Three samples were collected at each of sampling time described.

\section{Data analysis}

L. monocytogenes was enumerated (ISO 11290-2:1998/Amd 1:2004) in each sample and CFU/g were log 10 transformed. Average contamination at each sampling time was then calculated. The mean concentration of L. monocytogenes was plotted against minutes of cooking in a Survival curve. The slope of thermal reduction was then calculated and the decimal reduction time (D-value), i.e. time required at a specific temperature and under specified conditions to reduce a microbial population by one decimal to reduce $1 \log$, was calculated as $-1 /$ slope.

Finally, applying Linear $\square$ Bigelow Equation with $\mathrm{T}_{\text {ref }}$ of $70^{\circ} \mathrm{C}, \mathrm{D}_{\text {ref }}$ of $0.52 \mathrm{~min}$ utes and $\mathrm{Z}$ comprised to 6 and $8^{\circ} \mathrm{C}$, Van Asselt \& Zwietering (2006), the equivalent temperature exposed to L. monocytogenes during traditional cooking was calculated.

\section{Results}

\section{Questionnaire results}

Kebab house A. The kebab house A acquired the cone of kebab (chicken and turkey meat) frozen from the local industrial producer involved in the study, but the kebab was originally produced in Poland. The size of kebab was $7 \mathrm{~kg}$. The operator declared to defrost at room temperature the kebab before cooking and use electric knife. He declared not to use disinfectant on working surface but only clean with a detergent. The operator declared that sliced kebab did not remain in the collecting pan beyond the time needed to make panini and declared 10 hours to consume the cone of kebab and if a portion of kebab remained at the end of the day he put the portion at $-18^{\circ} \mathrm{C}$ wrapped in a food film.

Kebab house B. The kebab house B acquired the cone of kebab (chicken and turkey meat) frozen from Italy (local industrial producer involved in the study), the size of kebab was $40 \mathrm{~kg}$. The operator declared to defrost kebab during cooking and use electric knife. He declared not to use disinfectant on working surface but only clean with a detergent. He declared that sliced kebab did not remain in the collecting pan beyond the time needed to make panini and declared 11 hours to consume the cone of kebab. If a portion of kebab remained at the end of the day the operator used it for different preparations (recooked).

Kebab house $C$. The kebab house $\mathrm{C}$ acquired the cone of kebab (chicken and turkey meat) frozen from Germany, the size of kebab was $12 \mathrm{~kg}$. The operator declared 
to defrost kebab during cooking and use electric knife. He declared not to use disinfectant on working surface but only clean with a detergent and declared that sliced kebab did not remain in the collecting pan beyond the time needed to make panini. The operator declared 10 hours to consume the cone of kebab and usually no portion of kebab remained at the end of the day, if so he ate it at home.

Kebab Industrial Producer. The Industrial Producer declared to use calf, chicken and turkey meat. Aromas, spices, salt and other additives were used in the kebab production. The productive process consisted of 5 phases: 1 . boning meats, 2 . Marination of meat churning machine (2-6h at $\left.4^{\circ} \mathrm{C}\right), 3$. impaling of marinated meat on a vertical kebab stick and shaping into a cone and stored for one night at $4^{\circ} \mathrm{C}, 4$. packaging and labeling, 5. fast freezing at $-40^{\circ} \mathrm{C}$ and storage at $-18 \mathrm{C}$. The operator produced various sizes of kebab with skewers ranging from 7 to $50 \mathrm{Kg}$, with average daily machining of $1,000 \mathrm{~kg}$, and annual production of $220,000 \mathrm{~kg}$.

\section{Microbiological analysis}

Environmental samples collected during the working activity resulted always negative for Salmonella and L. monocytogenes. No Salmonella, Campylobacter and Shiga toxinproducing $E$. coli were detected in samples coming from the three gastronomy.

In Gastronomy A and B a contamination of L. monocytogenes was detected in raw kebab before cooking in both cases the enumeration results $<100 \mathrm{CFU} / \mathrm{g}(<10$ and 30 $\mathrm{CFU} / \mathrm{g}$, respectively). The pathogen was not detected in any of the following samples.

Molds and Sulfite-reducing bacteria growing under anaerobic conditions resulted always $<10 \mathrm{CFU} / \mathrm{g}$ (limit of quantification in enumeration methods used). In Table 1 the results of other microbiological enumeration obtained in the three kebab houses, are presented as mean and standard deviation $(n=9)$. The raw kebabs showed a high number of MAB (range: 4.04-8.86 log CFU/g) that was not completely destroyed in cooked sliced kebab ready to be assembled with other ingredients, in served panini. The effect of cooking was similar in the three kebab houses and ranged between 4.06 and $4.36 \mathrm{log}$ reduction in MAB count. Yeast and LAB showed a similar behavior, but the reduction due to cooking was less evident in LAB than in $\mathrm{MAB}(<1 \mathrm{log})$. It is interesting to note that Enterobacteriaceae and E.coli were always present in raw kebab, they were reduced under the quantification limit in cooked slices, but they return to be always enumerable in kebab that remained in the collecting pan and in ready to eat panini.
Efficacy evaluation of the traditional cooking process

During the official visits in the industrial productive plant $L$. monocytogenes was isolated in environmental samples (overshoes) and in churning machine. The pathogen was enumerated above 4 log $\mathrm{CFU} / \mathrm{g}$ in three batches of raw kebab produced during official visits. One of this batch was submitted to the cooking experiment.

The enumeration of $L$. monocytogenes $\left(\log _{10} \mathrm{CFU} / \mathrm{g}\right)$ survivors was plotted against time (min.) during traditional cooking and slicing process of the natural contaminated kebab (Figure 1). The raw meat was contaminated $4.5 \log _{10}$ and the pathogen was not detected in $25 \mathrm{~g}$ of product only after 150 minutes of cooking and slicing process, about in the middle of the cone of kebab. Continuing the traditional way of preparation and serving of kebab, L. monocytogenes survivors return detected in $25 \mathrm{~g}(<10$
$\mathrm{CFU} / \mathrm{g}$ ) at minutes 180 and rise to the level observed after 90 minutes at the end of the cone (after 220 minutes of cooking and slicing process).

The slope of thermal reduction calculated in the rectilinear part of the curve (between 0 and $150 \mathrm{~min}$.) was $-0.04 \log$

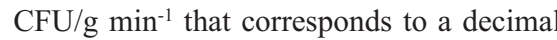
reduction time (D-value) of 25.9 minutes.

Applying Linear $\square$ Bigelow Equation with $\mathrm{T}_{\text {ref }}$ of $70^{\circ} \mathrm{C}$, Dref of 0.52 minutes and $\mathrm{Z}$ equal to $6^{\circ} \mathrm{C}$ or $8^{\circ} \mathrm{C}$, the temperature that corresponds to a D-value of 26 minutes for L. monocytogenes in the product traditionally cooked and sliced, was between $56.5^{\circ} \mathrm{C}$ and $60^{\circ} \mathrm{C}$, with $\mathrm{Z}=8$ and $\mathrm{Z}=6$, respectively.

\section{Discussion}

Kebab is a typical food served in small gastronomies (kebab houses) following traditional processes that can assure the safety

Table 1. Mean (standard deviation) of microbiological enumeration (log CFU/g) obtained in the three kebab houses sampled at different time during a working day (3 samples per sampling point and per gastronomy, $n=9$ determinations per parameter).

\begin{tabular}{lcccc} 
& Raw & Cooked sliced & Collecting pan & Panini \\
MAB & $6.29(2.43)$ & $3.21(1.30)$ & $3.67(1.50)$ & $4.39(2.83)$ \\
Enterob. & $2.93(0.36)$ & $1.00(0.00)$ & $1.74(0.81)$ & $4.17(2.94)$ \\
\hline E. coli & $1.56(0.49)$ & $1.00(0.00)$ & $1.30(0.20)$ & $1.62(1.07)$ \\
Yeast & $2.22(1.07)$ & $1.00(0.00)$ & $1.48(0.83)$ & $2.59(1.40)$ \\
\hline LAB & $3.22(1.03)$ & $2.41(1.30)$ & $2.65(1.30)$ & $3.48(1.14)$ \\
\hline
\end{tabular}

MAB: enumeration of mesophilic aerobic bacteria, LAB: enumeration of lactic acid bacteria.

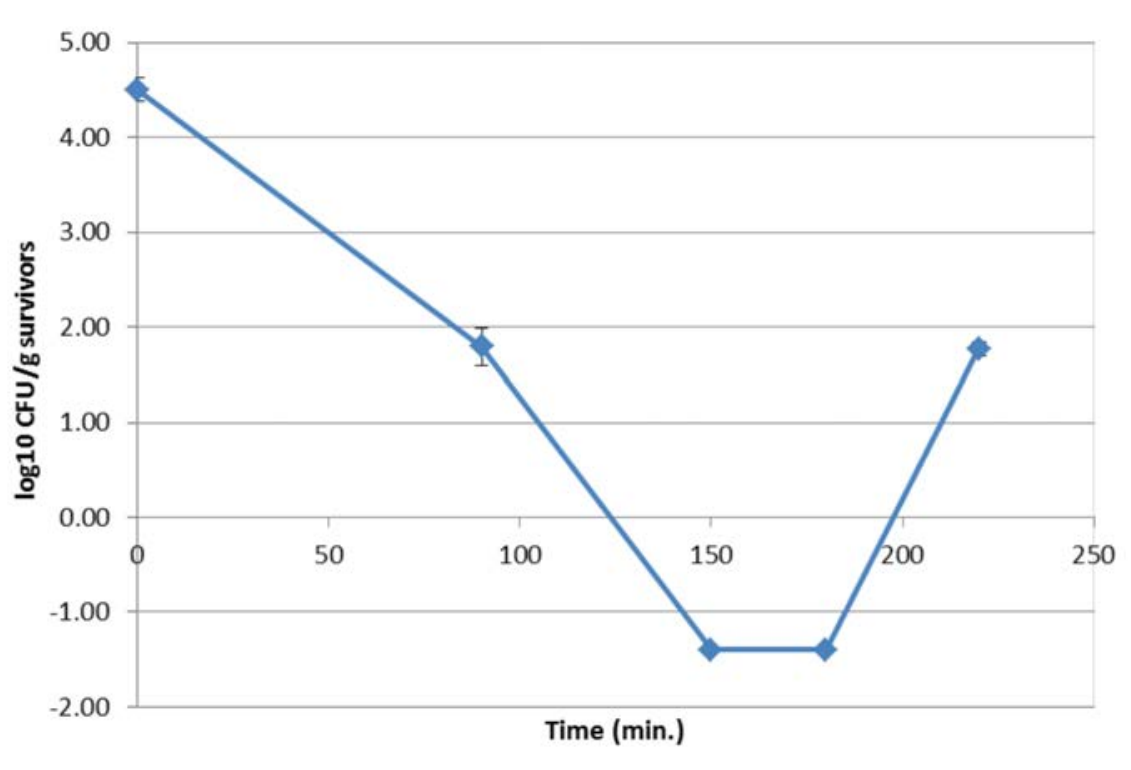

Figure 1. Dynamic of thermal inactivation of L. monocytogenes during traditional cooking process of a naturally contaminated kebab. 
of the product only if a full validated HACCP approach is correctly applied. In the hazard analysis the microbiological quality of raw materials have to be considered, but the hygienic working conditions, cooking methods, hygiene and sanitary conditions during the mechanical separation phases of the product and the time laps between preparation of sliced meat and the selling of panini to the final consumer play a fundamental role for the microbiological safety of the product.

Kebab houses visited during the study received frozen kebab from industrial continuous producers (Italian and German) but the microbiologic counts on raw kebab before cooking process show that concerns about hygiene process in production phases, remain present $(\mathrm{MAB}>6 \log \mathrm{CFU} / \mathrm{g}$, E.coli always present). These results are in accord with other studied (Vazgeçer et al., 2004; Gençer and Kaya, 2004; Kayışoğlu et al., 2003), that analyzed Turkish kebab samples at restaurants and are also in accord to an Italian study conducted in two towns of Sicily island (IT) Palermo and Messina (Ziino et al., 2013). Moreover, the answer received by the operators of kebab houses visited, although they cannot be considered representative of the totality of the operating restaurants, open important concerns about the hygienic formation of the staffs. In particular, the absence of adequate disinfection of working surface (only detergent is always present in the restaurants), the presence of wrong defrosting procedure in one case (room temperature) and a questionable defrosting procedure (during cooking) in the rest of the cases, need to be carefully evaluated during official audits. Recently, Liuzzo et al. 2016 have published a study aimed to ascertain if Döner kebabs sold on the Italian market comply with the labelling requirements of relevant EU legislation, finding that important hygienic-sanitary conditions for the protection of consumer's health and the safe use of the product were inadequate. In particular, regarding frozen status of kebab Authors report that a $67 \%$ of labels analyzed did not comply with the obligation of storage conditions specifications and $100 \%$ did not report the date of freezing (or the date of first freezing). These concerns have to be seriously considered in the process of improving safety of this traditional product by the Food Business Operators (FBO).

The focus of our study was the determination of the efficacy of the traditional way of preparing and serving of the döner kebab in reducing at acceptable level microbiological hazards. The principal question was: could the cooking and slicing of the meat for the selling of panini to the final con- sumer, be the control point for the contamination present in the raw kebab before cooking? Looking to the results obtained in kebab houses, the fraction of mesophilic aerobic bacteria (MAB) that survive in cooked and sliced meat was always relevant (mean $3.21 \log \mathrm{CFU} / \mathrm{g}$ ) that corresponds to a reduction of in average only about $3 \mathrm{log}$ during the cooking process. These unexpected results were also observed by Ziino et al. (2013), that report in cooked kebabs MAB values ranged from 1.78 to $6.30 \mathrm{log}$ $\mathrm{CFU} / \mathrm{g}$. Moreover, even if Enterobateriaceae seem to be efficiently controlled by the traditional cooking process, the results obtained in the collecting pan demonstrate that a fraction of this microorganisms survives the process and can grow above the detection limit of microbiological methods in the time laps between preparation of sliced meat and the selling of panini. Finally, the microbiological contamination detected in ready to eat panini suggests that raw ingredients (vegetables and souses) added in the final composition, worsen the picture. An evidence of that, could be found in Meldrum et al. 2009, that published a large study aimed to establish the microbiological safety of salad vegetables and sauces served in kebab takeaway restaurants in UK, finding that about $5 \%$ of salad vegetable and sauce samples were of unsatisfactory microbiological quality due to E. coli and/or Staphylococcus aureus levels at $10^{2} \mathrm{CFU} / \mathrm{g}$,with a fraction that results unacceptable due to $S$. aures above $10^{4} \mathrm{CFU} / \mathrm{g}$ and Salmonella presence.

The most important result of our study regards the natural contamination of $L$. monocytogenes observed in the production plant that gave us the opportunity to test the efficacy of the traditional way of cooking a naturally contaminated döner kebab in reducing at acceptable level the pathogens in ready to eat kebab panini. The D-value obtained (26 minutes) and the equivalent temperature determined (not above $60^{\circ} \mathrm{C}$ ) show that the thermal treatment applied to the frozen meat during kebab grilling and slicing activity could be insufficient in reducing pathogens contamination under acceptable levels. Moreover, during the experiment, depending on the level of kebab cone consumed, the contamination firstly decreased slowly, but at the end of the cone raised again at the levels observed at the beginning of the cooking experiment. Our results show that depending on the slope of the cone, the efficacy of the thermal treatment applied to the döner kebab cooked in the rotating stick of an open gas oven, could be tremendously different. Moreover, a second aspect of the kebab producing and serving could contribute to the observed results. It is important to remember that the cone of kebab is deeply contaminated during the process of marination and assembly of the different meat species and spices before shaping into a cone. So that, when the external part of the meat is exposed to the source of heat, the internal part of the meat (defrosted during the cooking process) that is exposed to much less effective thermal treatment, exposes the resident microorganisms even to permissive temperature for development. The widespread habit of slicing meat by using an electric knife could represent another point of concern, because the slices obtained are usually too thick to provide an efficient cooking of the inside part of the meat. These observations could justify the level of L. monocytogenes at the end of our cooking experiment, where the survivals rise again at the levels observed at the beginning of the trial.

\section{Conclusions}

In conclusion, the results obtained from the modelling of the survival curves of $L$. monocytogenes during the traditional way of cooking and serving of the kebab, in particular the equivalent temperature calculated $\left(\leq 60^{\circ} \mathrm{C}\right)$, open important questions regarding microbiological criteria that have to be applied to the product. Is the ready to eat kebab panini a product that belongs to the Food category 1.8 of EU REG. $2073 / 2005$ on microbiological criteria for foodstuffs (Meat products intended to be eaten raw, excluding products where the manufacturing process or the composition of the product will eliminate the Salmonella risk)? Is the frozen kebab before cooking a meat product or meat preparation (made from poultry or from other species than poultry) intended to be eaten cooked? Is the temperature applied to the frozen kebab during the cooking and splicing always sufficient to reduce at acceptable levels pathogens contamination of the product if present in raw meat or spices used during productive process?

In our opinion the microbiological safety of this product, very diffused in Europe and recently very diffused also in Italy, that from the nutritional point of view can be considered as an occasional substitute to one of the two main meals of the day (Panozzo et al., 2015) cannot be guaranteed by the traditional cooking process only. The risk of foodborne illnesses can be reduced through implementation and improvement of the hazard analysis critical control point (HACCP) concept, in particular, attention to the microbiological quality of prime materi- 
al used for the production of the cone of kebab (also in industrial continuous plants), formation of the staff of kebab houses on the good hygiene procedures for food preparation and service, validation of the defrosting procedure of the product in respect of the dimension of the cone and to the time estimated to be fully consumed, validation of the slices thickness obtained by the widely used electric knife and the thermal treatment obtained by the open oven, should be carefully considered to achieve the food safety of this product.

\section{References}

Advisory Committee on the Microbiological Safety of Food, 2004. Microbiological Control of Doner kebabs. Food Standards Agency, London.

AFNOR (Association Francaise de Normalization). 2008. AFNOR BRD 07/06-07/04:2008. Accessed December 2017. Available from: http://nf-validat i o n. a f n o r o r g / w p content/uploads/sites/2/2014/03/BRD07-06-07-04_en.pdf

AFNOR (Association Francaise de Normalization). 2009.AFNOR BRD 07/10-04/05:2009. Accessed December 2017. Available from: http://nf-valida$\mathrm{t}$ i o n. a f n o r . o r g / w p content/uploads/sites/2/2014/03/BRD07-10-04-05_en.pdf

Gençer VK, Kaya M, 2004 Microbiological quality and chemical composition of the döner. Turk J Vet Anim Sci 28:1097-103

Institute of Turk Standards, 1995. Doner kebab-raw (uncooked). The number of Turk Standards: 18859, Ankara, Turkey.

ISO/IEC 17025:2005. General requirements for the competence of testing and calibration laboratories. International Standardization Organization ed., Geneva, Switzerland.

ISO 4833-2:2013/Cor1:2014. Microbiology of the food chain - Horizontal method for the enumeration of microorganisms - Part 2: Colony count at 30 degrees $\mathrm{C}$ by the surface plating technique [Technical Corrigendum 1]

ISO 21528-2:2004 Microbiology of food and animal feeding stuffs - Horizontal methods for the detection and enumeration of Enterobacteriaceae - Part 2: Colony-count method

ISO 16649-2:2001 Microbiology of food and animal feeding stuffs - Horizontal method for the enumeration of beta-glucuronidase-positive Escherichia coli Part 2: Colony-count technique at 44 degrees C using 5-bromo-4-chloro-3indolyl beta-D-glucuronide

ISO 15213:2003 Microbiology of food and animal feeding stuffs - Horizontal method for the enumeration of sulfitereducing bacteria growing under anaerobic conditions

ISO 6579:2002/Cor.1:2004 Microbiology of food and animal feeding stuffs Horizontal method for the detection of Salmonella spp. TECHNICAL CORRIGENDUM 1

ISO 11290-1:1996/Amd 1:2004 Modification of the isolation media and the haemolysis test, and inclusion of precision data.

ISO 11290-2:2017 Microbiology of the food chain - Horizontal method for the detection and enumeration of Listeria monocytogenes and of Listeria spp. Part 2: Enumeration method

ISO 10272-1:2006 Microbiology of food and animal feeding stuffs - Horizontal method for detection and enumeration of Campylobacter spp. - Part 1: Detection method

Jöckel J, Stengel G, 1984. Döner kebabUnterschung und beurteilung einer türkischen spezialitat (Döner kebap manufacturing and assessment of Turkish specialities). Fleischwirtschaft 64:527-40.

Kayışoğlu S, Yılmaz I, DemirciM, Yetim H, 2003. Chemical composition and microbiological quality of the doner kebabs sold in Tekirdag market. Food Control 14:469-74.

Kruger KL, Davis ME, 1999. Döner kebabUnterschungen zum Handelsbrauch in Stuttgart (Commercial manufacturing of döner kebap in Stuttgart). Fleischwirtschaft 73:1242-8.

Meldrum RJ, Little CL, Sagoo S, Mithani V, McLauchlin J, De Pinna E, 2009. Assessment of the microbiological safety of salad vegetables and sauces from kebab take-away restaurants in the United Kingdom. Food Microbiol 26:573-7.

Liuzzo G, Rossi R, Giacometti F, Piva S, Serraino A, Mescolini G, Militerno G, 2016. Mislabelling of Döner kebab Sold in Italy. Ital J Food Saf 5:6149.

Panozzo M, Magro L, Erle I, Ferrarini S, Murari R, Novelli E, Masaro S, 2015. Nutritional Quality of Preparations Based on Döner kebab Sold in Two Towns of Veneto Region, Italy: Preliminary Results. Ital J Food Saf 4:4535.

RASFF, 2017. Rapid Alert System for Food and Feed (RASFF). Directorate General for Health and Consumer Protection, European Commission, Brussels. Available from: http://ec.europa.eu/food/food/rapidalert/index_en.htm.

Van Asselt ED, Zwietering MH, 2006. A systematic approach to determineglobal thermal inactivation parameters for various food pathogens. Int $\mathrm{J}$ Food Microbiol 107:73-82.

Vazgeçer B, Ulu H, Öztan A, 2004. Microbiological and chemical qualities of chicken döner kabab retailed on the Turkish restaurants. Food Control 15:261-4.

Ziino G, Guerrera G, Beninati C, 2013. Microbiological quality of kebabs sold in Palermo and Messina. Ital J Food Saf 2:77-80. 